\title{
Dexamethasone increases the activity but not the amount of choline-phosphate cytidylyltransferase in fetal rat lung
}

\author{
Seamus A. Rooney ${ }^{1}$, Douglas A. Smart ${ }^{1}$, Paul A. Weinhold ${ }^{2}$ \\ and Douglas A. Feldman ${ }^{2}$ \\ 'Du sion of Perinatal Medicine, Department of Pediatrics, Yale Unitersity School of Medicine. New Haren. CT ana -' Veter ans \\ Administration Medical Center and Department of Riological Chemistry; Unicersity of Michigan. Ann Arbor. MI IU.S.A.t
}

(Received 21 November 1989)

Key words: Choline-phosphate cytidyltransferase: Glu'ocorcicoid: Development: Hormone action: Phospholipid synthesis,

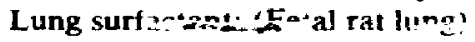

\begin{abstract}
The activity of choline-phosphate cytidylyltransferase is increased by glucocorticoids in late gestation fetal lung in association with increased phosphatidylcholine biosynthesis. Previous indirect data had suggested that the stimulatory effect of the homone was due to activation of existing enzyme rather than synthesis of new cytidylyltransferase protein. Using a rabbit antibody raised against purified rat liver choline-phosphate cytidylyltransferase, we have now quantitated the amount of the enzyme in fetal rat lung explants cultured with and without dexamethasone. Our results show that the hormone increased the activity of the enzyme but not the amount of cytidylyltransferase protein. Thus the stimulatory effect of dexamethasone on cytidy'yltransferase is due to activation of existing enzyme rather than induction of enzyme synthesis.
\end{abstract}

Choline-phosphate cytidylyltransferase (cytidylyltransferase; EC 2.7.7.15) is an important regulatory enzyme [1-3]. Its activity has been shown to be increased in association with increased de novo phosphatidylcholine biosynthesis in several systems [1-3]. The developing fetal lung is a useful model system in which to study the regulation of phosphatidylcholine biosynthesis. The alveolar surface of the lung is lined with a phosphatidylcholine-rich material, pulmonary surfactant, which is essential for nornal lung function [4]. Towards the end of gestation, as the fetal lung matures in preparation for air breathing, there is a surge in surfactant as well as phosphatidylcholine biosynthesis [3,5]. Fetal lung maturation, surfactant production and phosphatidylcholine biosynthesis are all enhanced by glucocorticoids, estrogen and thyroid hormone [3-5]. The hormone-induced increases in phosphatidylcholine biosynthesis are accompanied by increases in the activity of cytidylyltransferase [3].

When s!bcellular fractionation is carried out, cytidylyltransferase activity is found in both the cytosol and endoplasmic reticulum [1-3]. There is evidence from a number of systems that the membrane-bound

Correspondence: S.A. Rooney, Yale Dept. of Pediatrics, P.O. Box 3333, Hivw Haven, CT 06510, U.S.A. enzyme is the active form and that the increase in activity which accompanies the increase in phosphatidylcholine synthesis is due to enzyme transfer from cytosol to endoplasmic reticulum $[1,6,7]$. Subcellular translocation of the enzyme in association with in creased phosphatidylcholine synthesis. however. is not a universal phenomenon $[2,3,8]$. In the fetal lung. although microsoma! cytidylyltransferase activity was reported to be increased by hormones in some studies [9-11], the increases were generally found in the cytosol $[9,12-17]$, the fraction which also contained the bulk of the enzyme activity $[9,12,18]$.

In vitro cytosolic cytidylyltransferase activity can be increased by inclusion of lipids, such as phosphatidylglycerol $[12,19]$ or a mixture of oleic acid and phosphatidylcholine [20], in the assay mixture. The st imulatory effects of glucocorticoids $[9,15,16,21]$, estrogen $[12,13]$ and thyroid hormone [15] on cytosolic cytidylyltransferase in fetal lung were diminished or abolished when the assay was carried out in the presence of phosphatidylglycerol. Such data strongly suggested that the hormones increased the catalytic activity rather than the amount of cytidylyltransferase protein. In other systems there was also evidence that the increase in cytidylyltransferase activity was due to enzyme activation rather than protein synthesis $[1,6]$. Direct proof of this concept, however, has been lacking, since the mass of 
cytidylyltransferase protein was not quantitated. With the development of procedures for purification of cytidylyltransferase $[22,23]$ it has become possible to develop antibodies and by immunotitration directly determine enzyme mass. Using that approach, we have now addressed the question of whether the glucocorticoid-induced increase in cytidylyltransferase activity in fetal rat lung is due to an increase in the amount of enzyme or to activation of existiug enzyme.

Timed pregnant Sprague-Dawley rats were purchased from Charles River Breeding Laboratories (Wilmingtor, MA). The day after mating was consider day 1 ; term in rat is day 22 . On day 19 of gestation the dam was killed by decapitation and the fetuses were delivered by cesarean section under sterile conditions and weighed to confirm gestational age [24]. The lungs from all fetuses in each litter were combined to form a common pool of tissue from which explants $\left(1 \mathrm{~mm}^{3}\right)$ were then prepared. The fetal lung explants were cultured for $48 \mathrm{~h}$ as described previously [25] in $2 \mathrm{ml}$ of serum-free Waymouth's medium containing penicillin and streptomycin. The culture dishes were placed on a rocking platform (Bellco, Vineland, NJ) so that at any one time half the explants were covered by the culture medium and the other half exposed to the atmosphere of $95 \% \mathrm{O}_{2} / 5 \%$ $\mathrm{CO}_{2}$. Dexamethasone $(100 \mathrm{nM})$ was added to half of the dishes from each litter and the other half were used as controls. This concentration of dexamethasone has previously been shown to be more than sufficient to maximally stimulate the activity of cytidylyltransferase in 18-day fetal rat lung explants [9] with the maximum stimulation being achieved in approx. $20 \mathrm{~h} \mathrm{[21].} \mathrm{In} \mathrm{the}$ present study we used 19-day rather than 18-day fetuses to generate sufficient tissue so that one litter could be used in each experiment. In preliminary experiments the stimulatory effect of dexamethasone was essentially the same when explants of 19 day fetuses were cultured for only $24 \mathrm{~h}$ and when the hormone was added after $24 \mathrm{~h}$ as well as at the beginning of the $48 \mathrm{~h}$ culture period.

The medium was removed and the explants washed twice with ice-cold $0.9 \% \mathrm{NaCl}$ and once with $330 \mathrm{mM}$ sucrose $/ 10 \mathrm{mM}$ Tris-HCl $/ 1 \mathrm{mM}$ EDTA (pH 7.4). A $20 \%$ homogenate in the same buffer was prepared with a Potter-Elvehjem Teflon-glass homogenizer and centrifuged at $105000 \times g$ for $1 \mathrm{~h}$. Cytidylyltransferase was assayed in the supernatant fraction by measuring the rate of phospho[ $\left.\mathrm{Me}^{14} \mathrm{C}\right] \mathrm{choline}$ incorporation into CDPcholine as described by Gilfillan et al. [26]. Unless stated otherwise, $1.1 \mathrm{mM}$ phosphatidylglycerol [26] or $0.2 \mathrm{mM}$ phosphatidylcholine/ $0.2 \mathrm{mM}$ oleic acid [22] were included in the assay mixture.

Cytidyltransferase from rat liver was purfied as described previously [22]. Antiserum against the purified enzyme was raised in rabbits. The antiserum immunoprecipitated cytidylyltransferase activity in the cytosolic fraction of adult rat lung and liver. The IgG fraction isolated from the antiserum detected the $45000 M_{\mathrm{r}}$ subunit of cytidylyltransferase on Western blot analysis [27]. A detailed description of the antibody preparation and characterization will be subsequently published. To quantitate the amount of cytidylyltransferase in the fetal lung explants, antibody-antigen titrations were carried out using a fixed amount of antibody with variable amounts of $105000 \times g$ supernate [28]. The mixture of antiserem $(2 \mu \mathrm{l})$ and antiger. in a final volume of $315 \mu \mathrm{l}$ of $10 \mathrm{mM}$ Tris- $\mathrm{HCl} / 1 \mathrm{mM}$ EDTA $/ 1.9 \mathrm{mM}$ dithiothreitol (pH 7.4) was incubated at $4^{\circ} \mathrm{C}$ for $18 \mathrm{~h}$. A $20 \%$ suspension of Protein $A(50 \mu 1)$ was then added and after mixing several times over a $1 \mathrm{~h}$ period at $4^{\circ} \mathrm{C}$ the antibody-antigen complex was removed by centrifugation at $12000 \times g$ for $10 \mathrm{~min}$. Cytidyltransferase activity was then assayed using $90 \mu 1$ of the supernatant. The units of enzyme activity ( $\mathrm{pmol} / \mathrm{min}$ ) remaining after immunoprecipitation were plotted against the original

TABLE I

The effect of dexamethasone on the activity and amount of cytidyly/trcnsferase in fetal rat lung explants

Explants of 19-day fetal rat lung were cultured $\pm 100 \mathrm{nM}$ dexamethasone for $48 \mathrm{~h}$ after which cytidylyltransferase activity and equiva' nce points in the 1 US $000 \times g$ supernatant fraction were measured. Cytidylyltransferase activity was measured $\pm 1.1 \mathrm{mM}$ phosphatidylglycerol (FG) in the assay mixture. Phosphatidylglycerol was included in the assay mixture when equivaleilce points were determined. The data are means $\pm S$. $E$ from four litters and were analyzed statistically with Student's $t$-test for paired samples.

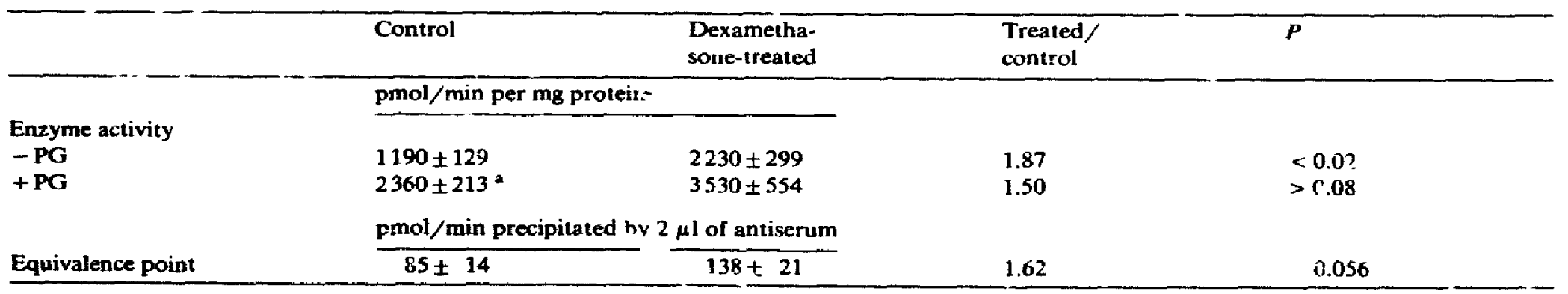

- Cytidylyltransferase activities in the control group were signaficantly different $(P<0.05)$ when assayed with and without addition of phosphatidylglycerol to the assay mixture. 
and the equivalence point (the amount of enzyme removed by the antibody) determined [28]. Immunotitration using a fixed amount of cytidylyltransferase and variable amounts of antibody was carried out similarly.

Protein was assayed by the method of Lowry et al. [29] using bovine serum albun in as standard. Phospho$\left[\mathrm{Me}^{14} \mathrm{C}\right.$ ]choline was obtairıd from Amersham (Arlington Heights, IL), culture medium from Gibco (Grand Island, NY) and dexamethasone, Protein A (lyophilized cell powder from Staphylococcus aureus) and other biochemicals from Sigma (St. Louis, MO).

The effect of dexamethasone on the activity of cytidylyltransferase in feta! rat lung explants is shown in Table I. When assayed without addition of phosphatidylglycerol to the reaction mixture, the hormone increased cytidylyltransferase activity by $87 \%$ (range: $57 \%$ to $141 \%$ ). This degree of stimulation was similar to that previously reported for explants of 18-day fetal rat lung [9.15,21]. As also reported previously $[9,15,16,21]$, the stimulatory effect of dexamethasone was diminished when cytidylyltransferase activity was measured in the presence of phosphatidylglycerol (Table I). Phosphatidylglycerol doubled the activity in the control group but only increased that in the dexamethasone-treated group by $58 \%$. Thus the stimulatory effect of the hormone was reduced from $87 \%$ to $50 \%$ when the assay was carried out in the presence of phosphatidylglycerol. However, as the stimulatory effect of phosphatidylglycerol was variable, the dexamethasone-induced increase in cytidylyltransferase activity ranged from $6 \%$ to $83 \%$ in this assay condition.

Fig. 1 shows that rabbit antiserum raised against rat liver cytidylyltransferase immunoprecipitated the en-

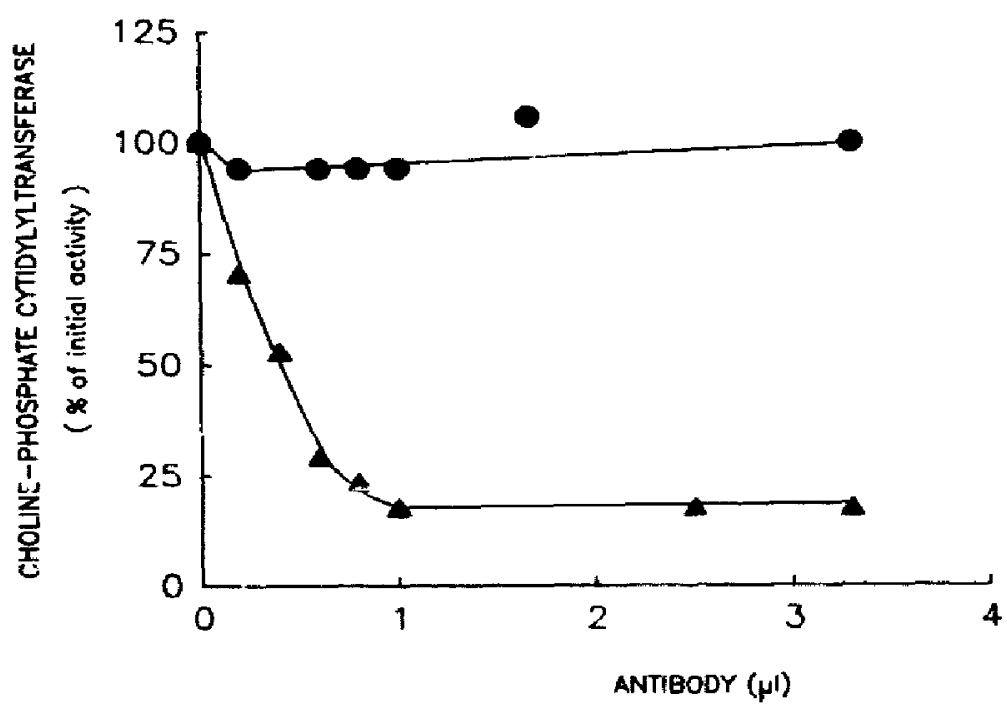

Fig. 1. Immunotitration of sytidylyltransferase. Fetal type Il cell $100000 \times g$ supernate containing a fixed amoust cytidvlyltransfera: (165 $\mathrm{pmol} / \mathrm{min}$ ) was incubated with different amounts of antiserum against rat liver cytidylyltransferase (A) or serum from a control rabbit (O) after which cytidylyltransferase activity was measured in the presence of phosphatidylcholine oleic acid. These data are from a typical experiment.

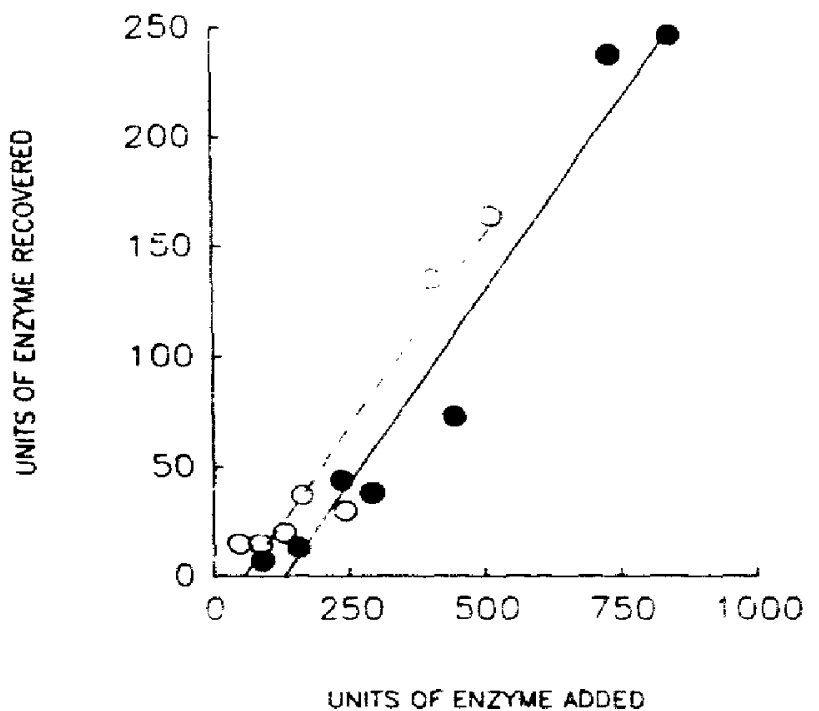

Fig. 2. Equivalence point determination by immunotitration. A fixed amount of antiserum $(2 \mu 1)$ was incubated with increasing amounts of $105000 \times g$ supernate from control $\left(\rho_{-}-0\right)$ and dexamethasonetreated (- $)$ fetal rat lung explants after which cytidylyltransferase was assayed in the presence of phosphatidylglycerol. The equivalence point. units of cytidylyltransferase (pmol/min) immunoprecipitated. is the intercept on the abscissa when the initial versus the final units of enzyme were plotted. These data are from one experiment. Initual cytidylyltransferase activities in the control and dexamethasone-treated explatts were 1123 and $2708 \mathrm{pmol} / \mathrm{min}$ per mg frotein when assayed without phosphatidylglycerol and were increased to 2392 and $4380 \mathrm{pmol} / \mathrm{min}$ per $\mathrm{mg}$ protein when phosphatidylglycerol was included in the assay.

zyme in the supernatant fraction of type II cells which were isolated from 19-day fetal lungs as described by Viscardi et al. [11]. Serum from a control rabbit had no effect on cytidylyltransferase activity. A similar immunoprecipitation profile was obtained when the enzyme in control fetal rat lung explants was incubated with the antiserum. This antiserum was, therefore, used to quantitate the amount of cytidylyltransferase in the control and dexamethasone-treated explants. In these experiments, cytidylyltransferase was assaved in the presence of phosphatidyiglycerol. since the immunoprecipitation data were difficult to interpret when the assay was carried out in its absence. Although the stimulatory effect of the hormone was greater when the enzyme was assayed without addition of phosphatidyiglycerol, it is possible that the presence of inactive enzyme, which could be immunoprecipitated by the antibody, compromised the results.

The result of an immunotitration using a fixed amount of antibody and variable amounts of supernate is shown in Fig. 2. In that experiment, dexamethasone increased cytidylyltransferase activity, assayed in the presence of phosphatidylglycerol, by $83 \%$ and increased the amolint of activity inımunoprecipitated by $107 \%$. When the stimulatory effect of the hormone on enzyme activity was less, its effect on the amount of activity immunoprecipitated was correspondingly less. As shown 


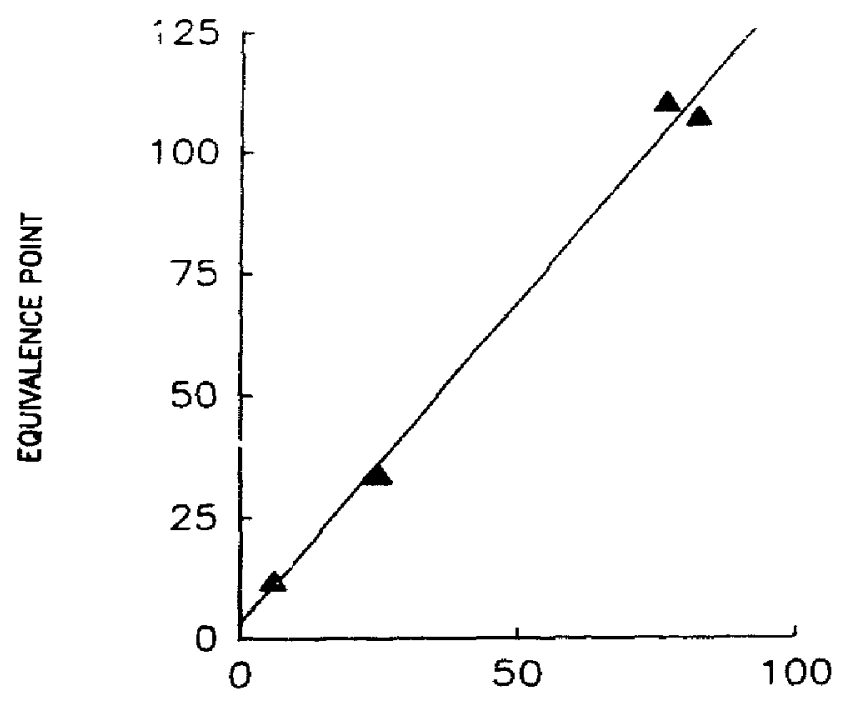

CYTIDYLYLTRANSFERASE ACTNITY

Fig. 3. Correlation between the dexamethasone-induced increases in cytidylyltransferase activity and equivalence point. The data, expressed as percentage increase over controls, are from the experiments described in Table l. Cytidylyltransferase was assayed in the presence of phosphatidylglycerol. The regression coefficient $(r=0.996)$ is $\$$ tatistically significant ( $P<0.005$ ).

in Fig. 3, there was a highly significant correlation between the dexamethasone-induced increase in cytidylyltransferase activity and enzyme units immunoprecipitated. As shown in Table $i$, the same amount of antibody removed $62 \%$ more units of enzyme from the treated group than the control and this increase was similar in magnitude to the $50 \%$ increase in cytidylyltransferase activity. Since the antibody should react with the same amount of protein in both the control and dexamethasone-truated groups these data show that the hormone-induced increase in cytidylyltransferase activity is due to an increase in enzyme activity rather than mass.

Glucocorticoids have long been known to accelerate lung maturation, stimulate surfactant production and increase lung phosphatidylcholine biosynthesis in the late gestation fetus [3-5]. Consistent with cytidylyltransferase being a regulatory enzyme in phosphatidylcholine biosynthesis $[1,2]$, glucocorticoids have been repoitu , in -rease the activity of this enzyme in the fetal lung [?]. 1 .. - stimulatory effect of the hormone was shown to be mediated by the glucocorticoid receptor and dependent on transcriptior and synthesis of new protein [9]. The stimulatory effect $c^{\text {? }}$ glucocorticoids on cytidylyltransferase activity could be te nsiderably diminished when the enzyme activity was increased by inclusion of phusphatidylglycerol in the assay mixture $[9,15,16]$. These indirect data suggested that the hormone-induced increase in activity was due to activa- tion of exisiing enzyme rather than synthesis of new enzyme protein. As at least some stimulation was still apparent $[9,15-17]$ even when the enzyme was assayed in the presence of sufficient phosphatidylglycerol to maximally activate the enzyme in vitro $[12,19,26]$ the possibility of glucocorticoid induction of cytidylyltransferase synthesis remained. In the present study we have now shown that the glucocorticoid-induced increase in cytidylyitransferase activity is not due to an increase in the amount of enzyme and must therefore be due to enzyme activation.

The increased cytidylyltransferase activity which accompanies increased phosphatidylcholine biosynthesis in other systems has also been attributed to enzyme activation rather than increased synthesis $[1,6]$. However, because of difficulty in obtaining an antibody which immunoprecipitates sytidylyltransferase [30], the mass of the enzyme has not generally been quantitated. To our knowledge there is only one previous study in which the mass of cytidylyltransferase was measured. In that study Choy et al. [31] generated a chicken antibody to rat liver cytidylyltransferase with which they showed that the amount of the enzyme was not decreased in association with decreased phosphatidylcholine synthesis in the livers of choline-deficient rats.

The finding that the activity but not the amount of cytidylyltransferase is increased by glucocorticoids in fetal lung suggests two major questions. Firstly, how is cytidylyltransferase activity enhanced by the hormone? Secondly, since the stimulatory effect of the hormone on cytidylyltransferase activity [9] as well as on phosphatidylcholine biosynthesis $[9,32]$ is dependent on protein synthesis, which protein or proteins are induced? A number of mechanisms for activation of cytidylyltransferase have been proposed [1] and there is evidence that each of them can occur in the fetal lung. These include activation by dephosphorylation [33], free fatty acids [18] and phospholipids [12,19] as well as translocation from the cytosol to a membrane fraction of the cell [18] possibly promoted by one or more of the above activation mechanisms. The activity of fatty-acid synthase (EC 2.3.1.85) has been reported to be increased by glucocorticoids in fetal ra: $[34,35]$ and human [36] lung. There is evidence that this enzyme is induced by the hormone as both its activity and amount were increased [35]. We have also reported that inhibition of de novo fatty acid synthesis results in abolition of the stimulatory effect of dexamethasone on cytidylyltransferase activity in fetal rat lung explants [21]. A plausible hypothesis, therefore, is that glucocorticoid induction of fatty-acid synthase results in increased synthesis of fatty acids which in turn, either directly or after incorporation into phosphol pids, activate cytidylyltransferase [37].

This work was supported by research grants HL43320 (SAR), HD-2199? (PAW) and HD-02871 (PAW) 
from the National Institutes of Health, United States Public Health Service.

\section{References}

1 Pelech, S.L. and Vance, D.E (1984) Biochim. Biophys. Acta 779 217-251.

2 Tijburg, L.B.M., Geeten, M.J.H. and Van Golde, L.M.G. (1989) Bicchim. Biophys. Acta 1004, 1-19.

3 Rooney, S.A. (1985) Am. Rev. Respir. Dis. 131, 439-460.

4 Van Gelde, L.M.G. Batenburg. J.J. and Robertson, B. (1988) Physiol. Rev. 68, 374-455.

5 Post, M. and Van Golde, L.M.G. (1988) Bjochim. Biophys Acta 947, 249-286.

6 Steight, R. and Kent, C. (1983) J. Biol. Chem. 258, 831-835.

7 Terce, F., Pscond, M., Ribbes, G., Chap. H. and Douste-Blazy. L. (1988) J. Biol. Chem. 263, 3142-3149.

8 Hatch, G.M., O.. K. and Choy, P.C. (1989) Biochem. Cell Biol. 67, 67-77.

9 Rooney, S.A., Dynia, D.W., Smart. D.A., Chu, A.J., Ingleson, L.D., Wilson, C.M. and Gross, I. (1986) Biochim. Biophys. Acta 888, $208-216$.

10 Post, M. (1987) Biochem. J. 241, 291-296

11 Viscardi, R.M., Weinhold, P.A., Beals, T.M. and Simon, R.H. (1989) Exp. Lung Res. 15, 223-237.

12 Chu, A.J. and Rooney, S.A. (1985) Biochim. Biophys. Acta 834. 346-356.

13 Possmayer, F., Casola, P.G., Chan, F., MacDonald. P., Ormseth. M.A., Wong, T., Harding, P.G.R. and Tokmakjian, S. (1981) Biochim. Biophys. Acta 664, 10-21.

14 Rooney, S.A., Gobran, L.I., Marino, P.A., Maniscalco, W.M. and Gross, I. (1979) Biochim. Biophys. Acta 572, 64-76.

15 Gross, 1., Dynia, D.W., Wilson, C.W., Ingleson, L.D., Gewolb, I.H. and Rooney, S.A. (1984) Pediatr. Res. 18, 191-196.

16 Brehier, A. and Rooney, S.A. (1981) Exp. Lung Res. 2. 883-890.

17 Haltman, M. (1984) Biochim. Biophys. Acta 795. 67-78.

18 Weinhold, P.A., Rounsifer, M.E., Williams, S.E., Brubaker. PG. and Felriman, D.A. (1984) J. Biol. Chem. 259, $10315-10321$.
19 Feldman. D.A. Kovac. C.R.. Drangins. P.L. and Weinhold. P..A. (1978) J. Bint. Chem. 253.4980 4986.

20 Feldman. D.A.. Rounsifer, M.E. and Weinhold, P.A. (1985) Biochim. Biophys, Acta 429, 429 $\ldots+47$.

21 Xu. Z.X.. Smart. D.A. and Rinney, S.A. (1990) Biochim. Biophys. Acta 1044, 70-76.

22 Weinhold. P.A. Rounsifer. M.E. and Feldman, D.A. (1986) J. Biol. Chem. 261, 5104-5, 10

23 Feldman, D.A. and Weinthoid. P.A. (1987) J. Biol. Chem. 262. 9075-9081

24 Rooney, S.A. Gobran. L.I. and Chu. A.J. (1986) Pediatr. Res. 20, $545-550$.

25 Gross, I., Wilson, C.M.. Ingleson. L.D.. Brehier. A and Rooncy, S.A. (1979) Biochim. Biophys. Acta 575. 375-383.

26 Gilfillan. A.M. Smart. D.A. and Rooney. S.A. (1985) Biochim. Biophys. Acta 835. 141-146.

27 Weinhold. P.A.. Rounsifer. M.E.. Charles. L. and Feldman. D.A (1989) Biochim. Biophys. Acta 1006. 299-310.

28 Emest. M.I. and Feigelson. P. (1979) in Glucronicoid Hormone Action (Baxter. J.D. and Rousseau. G.G., eds.). pp. 219-241, Springer. Berlin.

29 Lowry, O.H., Rosebrough, N.J., Farr, A.L. and Randall. R.J. (1951) J. Biol. Chem. 193. 265-275.

30 Sanghera, J.S. and Vance. D.F. (1989) J. Biol. Chem 264. 1215 1223 .

31 Choy. P.C. Schneider. W.J. and Vance. D.E. (197h) Eur. J. Bio chin $85,189-193$.

32 Gross. I.. Ballard. P.L.. Ballard, R.A.. Jones. C.T. and Wilson. C.M. (1983) Endocrinology 112. 829-837.

3. Radika K and Possmayer, F. (1985; Binchem. J. 222. 833-840

i4 Pope. T.S. and Rooney. S.A. (1997) Biorhtm. Hiophys. Acta 918. $141-148$.

35 Pope, T.S. Smart. D.A. and Rooney, S.A. (1988) Biochim. Biophys. Acra 959. i67-177.

36 Gonzales. L.W.. Ertsey. R.. Bailard, P.L.. Froh. D.. Goerke. J. and Gonzales. J. (1990) Biochim Biophrs Acta 104\% i 1:

37 Rooney, S.A. (1989) Am. J. Physiol. 257. L195-L-201. 